\title{
Availability of novel contraceptive methods in Canada
}

\author{
Polly Tsybina, Kyle Canton \\ Faculty Reviewer: Shannon Arntfield, MD, MSc, FRCSC (Department of Obstetrics and Gynecology)
}

Numerous contraceptive options are available in Canada, but studies show that Canadian women most often use the following three methods: condoms (54\%), oral contraceptives (44\%), and withdrawal (12\%). ${ }^{1}$ Typical failure rates of these methods are $18 \%$, $9 \%$, and $22 \%$, respectively. These statistics may be linked with the finding that one third of Canadian women have at least one induced abortion in their lifetime.

Contraceptive failure is lower among long-acting and permanent contraceptive options, primarily because user adherence is taken out of the equation. However, Canadian women appear reluctant to use long acting options such as intrauterine devices (IUDs), perhaps because of associated adverse events. For example, some $20 \%$ of women discontinue IUDs within the first year of use due to pelvic pain, irregular bleeding, or spontaneous expulsion. ${ }^{2}$ DMPA (Depo-Provera) is often discontinued because of weight gain commonly experienced by its users. ${ }^{3}$ Thus, there remains a need for novel contraceptive choices for women who are unable to use the formulations currently available in Canada.

One promising alternative not yet available in Canada is Nexplanon, an etonogestrel (progestin only) implant inserted into the inner, upper arm. In adults, its efficacy is higher than that of oral contraceptives and IUDs, at $>99 \%$ (efficacy studies in women under 18 years of age are not yet available). ${ }^{4}$ Effectiveness lasts up to three years, and the approach for insertion is less invasive than IUDs. Side effects are similar to other contraceptive methods, with the most common being breakthrough bleeding, depression, and mood swings. Abnormal bleeding is the most common reason for discontinuation, but notably, more than three quarters of women retain their implant for two years or more. Nexplanon is also more cost effective than both OCP and hormonal or copper IUDs, as seen from a study in France. ${ }^{5}$ The combination of superior effectiveness, a simpler and less invasive insertion, and increased cost effectiveness makes Nexplanon a preferable alternative to contraceptive options otherwise available to Canadian women. However, the manufacturer of Nexplanon (Merck) recently failed to satisfy Health Canada's requirements for new contraceptive devices, and it is uncertain whether the company will re-apply for approval. ${ }^{6}$

Another unavailable but promising contraceptive option is Cerazette, a progestin only pill (POP) that uses desogestrel as its active ingredient. POPs are important options among women who prefer or require a non-estrogen containing contraceptive, due to either medical contraindications to estrogen, patient preference, side effect profile, or physiologic states such as breastfeeding. Most POPs function by thickening the uterine mucus lining. However, Cerazette also prevents ovulation in $97 \%$ of cycles. ${ }^{7}$ What makes Cerazette truly stand out, however, is its margin for timing variabilities. Most POPs must be taken within a 3 hour window each day to ensure effectiveness, whereas Cerazette allows a 12 hour window. ${ }^{8}$ This offers women much greater flexibility without compromising efficacy.

It is clear that Cerazette and Nexplanon offer advantages over the contraceptive options currently available on the Canadian market. There is a wealth of safety data available for these formulations as they have been in use for some 20 years. Etonogestrel's safety has been demonstrated in clinical trials including over 2,000 women.9-12 Some 1,000 women have taken part in a clinical trial specifically looking at safety of desogestrel-only contraceptive pill. ${ }^{13}$ Also, there have been studies using desogestrel for treatment of other conditions, such as headaches and endometriosis. ${ }^{14-15}$ Moreover, there are numerous studies where desogestrel was combined with ethinyl estradiol, as it is also a part of several combined OCP formulations. ${ }^{16-17}$ Finally, many countries have a system for reporting and surveillance of adverse events (for example, FDA adverse event reporting system available on www.fda.gov), and neither desogestrel nor etonogestrel have raised concerns once approved for use. With a need for these contraceptive options and the abundance of research done to date, it seems surprising that these drugs are not available in Canada.

Health Canada approval process for contraceptives is notorious for delaying or preventing new contraceptives from entering the market. Troskie and colleagues compared the data for new hormonal contraception entering the market in Canada, USA, and UK. ${ }^{18}$ Canada approved fewer devices than the two other countries between 2000 and 2015, and it took significantly longer for Health Canada to approve new drugs: $30 \%$ longer than the corresponding regulatory agency in the US, and 50\% longer than the UK. Approval times for contraceptives in Canada likely lag chiefly due to the stringency of the guidelines required by Health Canada. ${ }^{19}$ Namely, the guidelines dictate that clinical trials for new hormonal contraceptives to be introduced in Canada require 800-900 participants, 20,000 cycles of exposure, and multiple endometrial biopsies for multiparous women enrolled in the trial. Other regulatory agencies do not require endometrial biopsies, and the FDA, for example, sets the standard at 10,000 cycles with 200 women enrolled, unless the hormone is a new molecular entity. ${ }^{20}$

One could argue that these guidelines are intended to protect consumers, and, as Health Canada explains, biopsies are important to distinguish uterine bleeding that is a side effect of the contraceptive from more insidious pathology. However, progesterone analogues are known to decrease risk of endometrial cancer, and are used to treat endometrial hyperplasia, ${ }^{21-22}$ so it remains unclear why endometrial biopsy is a requirement. For etonogestrel implants, there have been no reports of endometrial atypia or cancer as adverse events. ${ }^{9-12}$ Additionally, etonogestrel has been used in Canada 
for years as a component of another contraceptive device, NuvaRing, with no adverse effects on endometrial histology. ${ }^{23}$

It is clear that Canada lags behind in its approval of novel contraceptives, arguably due to barriers by Health Canada that appear unnecessary. This limits the options available to Canadian women, preventing access to more effective, less invasive, and more flexible contraceptives such as Nexplanon and Cerazette. In order for Canadian women to have the best available choices for contraception, policy should be amended to remove the unnecessary barriers and shorten the approval process. We invite readers to contact their members of parliament as well as the minister of health with requests to improve the availability of novel contraceptives to Canadian women.

\section{REFERENCES}

1. Black A, Guilbert E, Costescu D, et al. Canadian Contraception Consensus (Part 1 of 4). J Obstet Gynaecol Can. 2015. 37(10):S1-S28.

2. Lee G, Ekbladh, L. Short-term IUD discontinuation at an urban center. Contraception. 2012. 85(3): 324-5.

3. Paul C, Skegg DC, Williams S. Depot medroxyprogesterone acetate: Patterns of use and reasons for discontinuation. Contraception. 1997. 56(4):209-14

4. Sanders J, Turok DK, Gawron LM, et al. Two-year continuation of intrauterine devices and contraceptive implants in a mixed-payer setting: a retrospective review. Am J Obstet Gynecol. 2017. Accepted manuscript.

5. Lafuma A, Agostini A, Linet T, et al. Cost-effectiveness of Nexplanon (Etonogestrel implant) compared to other reimbused contraceptive methods in France based on real life data. Value Health. 2015. Nov;18(7):A735-6.

6. Barton, A. Stringent Health Canada requirements restrict access to hormonal implants. Globe and Mail. 2015. Acccessed online March 10, 2017: http://www.theglobeandmail.com/life/health-and-fitness/ health/stringent-birth-control-requirements-keep-options-limited-for-canadians/article23882944/

7. Rice CF, Killick SR, Dieben T, et al. A comparison of the inhibition of ovulation achieved by desogestrel 75 micrograms and levonorgestrel 30 micrograms daily. Hum Reprod. 1999. Apr;14(4):982-5.

8. Korver T, Klipping C, Heger-Mahn D, et al. Maintenance of ovulation inhibition with the 75-xg desogestrel-only contraceptive pill (Cerazette $^{\circledast}$ ) after scheduled 12-h delays in tablet intake. Contraception. 2005. Jan;71(1): 8-13.

9. Meirik O, Brache V, Orawan K, et al. A multicenter randomized clinical trial of one-rod etonogestrel and two-rod levonorgestrel contraceptive implants with nonrandomized copper-IUD controls: Methodology and insertion data. Contraception. 2013. Jan;87(1):113-20.

10. Funk S, Miller MM, Mishell DR Jr, et al. Safety and efficacy of Implanon, a single-rod implantable contraceptive containing etonogestrel. Contraception. 2005. May;71(5):319-26.

11. Croxatto HB, Urbancsek J, Massai R, et al. A multicentre efficacy and safety study of the single contraceptive implant Implanon. Implanon Study Group. Hum Reprod. 1999. Apr;14(4):976-81.

12. Mommers E, Blum GF, Gent TG, et al. Nexplanon, a radiopaque etono Agestrel implant in combination with a next-generation applicator: 3 -year results of a noncomparative multicenter trial. Am J Obstet Gynecol. 2012. Nov;207(5):388.el-388.e6.

13. Korver T. A double-blind study comparing the contraceptive effica- cy, acceptability and safety of two progestogen-only pills containing desogestrel $75 \times \mathrm{g} /$ day or levonorgestrel $30 \times \mathrm{g}$ /day: Collaborative Study Group on the Desogestrel-containing Progestogen-only Pill. Eur J Contracept Reprod Health Care. 1998. Aug;3(4):169-78.

14. Merki-Feld G, Imthurn B, Langner R, et al. Headache frequency and intensity in female migraineurs using desogestrel-only contraception: A retrospective pilot diary study. Cephalalgia. 2013. Apr;33(5):340-6.

15. Leone Roberti Maggiore U, Remorgida V, Scala C, et al. Desogestrel-only contraceptive pill versus sequential contraceptive vaginal ring in the treatment of rectovaginal endometriosis infiltrating the rectum: a prospective open-label comparative study. Acta Obstet Gynecol Scand. 2014. Mar;93(3):239-47.

16. Endrikat J, Dusterberg B, Ruebig A, et al. Comparison of efficacy, cycle control, and tolerability of two low-dose oral contraceptives in a multicenter clinical study. Contraception. 1999. 60(5):269-74.

17. Koetsawang S, Charoenvisal C, Banharnsupawat L, et al. Multicenter trial of two monophasic oral contraceptives containing $30 \mathrm{mcg}$ ethinylestradiol and either desogestrel or gestodene in Thai women. Contraception. 1995. Apr;51(4):225-9.

18. Troskie C, Soon JA, Albert AY, et al. Regulatory approval time for hormonal contraception in Canada, the United States and the United Kingdom, 2000-2015: a retrospective data analysis. CMAJ Open. 2016. Nov;4(4):E654-60.

19. Health Canada Guidance Documents. Guidance for Industry: Clinical Development of Steroidal Contraceptives Used by Women. Published by authority of the Minister of Health. Accessed on March 11, 2017: http://www.hc-sc.gc.ca/dhp-mps/prodpharma/applic-demande/ guide-ld/oral/contracep-eng.php.

20. FDA Advisory Committee Briefing Document. Prepared by the Division of Reproductive and Urologic Products Office of Drug Evaluation III. December 21, 2006. General Meeting on Contraceptives. Accessed on March 8, 2017: https://www.fda.gov/ohrms/dockets/ac/07/briefing/2007-4274b1-01-FDA.pdf.

21. Deligdisch, L. Hormonal Pathology of the Endometrium. Mod Pathol. 2000. Mar;13(3):28-94.

22. Black A, Guilbert E, Costescu D, et al. Canadian Contraception Consensus (Part 3 of 4): Chapter 8 - Progestin-Only Contraception. J Obstet Gynaecol Can. 2016. Mar;38(3):279-300.

23. Bulten J, Grefte J, Siebers B, et al. The combined contraceptive vaginal ring (NuvaRing) and endometrial histology. Contraception. 2005. Nov;72(5):362-5. 